\title{
Predicting outcome in acute cardiotoxicity based on Glasgow coma scale (GCS) and modified APACHE II score (MAS)
}

\author{
Meray M. Shokry ${ }^{1}$, Maha A. Hilal ${ }^{1}$, Sharaf E. Shazly Abdalla ${ }^{2}$ and Ahmed M. Said, ${ }^{1}$ \\ ${ }^{1}$ Department of Forensic Medicine \& Clinical Toxicology, Faculty of Medicine, Sohag University, Sohag, Egypt. \\ ${ }^{2}$ Department of Internal medicine, Faculty of Medicine, Sohag University, Sohag, Egypt.
}

\begin{abstract}
Introduction:

Acute cardiotoxicity patients can have adverse effects that may lead to intensive care unit (ICU) admission. Because of limited ICU beds, triage and stratification of cases into different groups according to survival is a must nowadays. Many scoring systems have been as a tool for triage and improve ICU quality management. This study aims to evaluate the role of GCS (Glasgow coma scale) and MAS (Modified Acute Physiology And Chronic Health Evaluation ) as effective scoring system in predicting mortality in acute cardiotoxicity Methods: A prospective study was carried on 100 patients with acute cardiotoxicity by drugs and toxins known to cause cardiac injury admitted to Sohag Hospitals. Results 94\% of patients had survived 4 of which discharged with complication . By ROC curve analysis to assess the predictor of outcome of acute cardiovascular toxicity, it was found that MAS score at cut off value $>11.5$ had sensitivity $100 \%$ and specificity $74.5 \%$, GCS at cut off $<9.5$ had sensitivity $100 \%$ and specificity $72.3 \%$.The accuracy rate of GCS was $(92.4 \%)$ while that of MAS was (90.8\%). Conclusion: GCS and MAS can be used as simple predictor tools of mortality in acute cardiotoxicity. Recommendation: GCS and MAS may be used as simple triage tools in acute cardiotoxicity patients in ICU to improve quality management and utilizing hospital resources.

Key words Cardiotoxicity, MAS, GCS, APACHE II.
\end{abstract}

\section{Introduction}

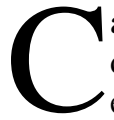

ardiovascular failure remains a leading cause of death in severe acute drug intoxication (Johnson

et al, 2013). According to records from the Poison Control Center of Ain Shams University Hospitals, Egypt, the annual report in 2014 cardiovascular drugs intoxication accounts for $1.67 \%$ of the total reported poisoning cases (Hussien et al, 2018).

Severe cases of drug overdose usually require intensive care unit (ICU) admission. So, various scoring systems have been employed for proper identification and disposition of cases improving ICU quality management especially with shortage of ICU beds (Mood et al., 2011).

Glasgow coma scale (GCS) has been used now in several emergency departments as an indicator for the neurological status of patients with impaired consciousness regardless of the primary etiology. Poisoning with drugs influences the brain biochemically, causes brain damage hence affecting level of consciousness. The GCS has been performed evaluation of patients admitted to ICU regarding outcome and recovery.

Four scoring systems had an acceptable to excellent outcome prediction in patients with mixed drug poisoning (MDP) inducing coma. They include 1st GCS within 24 hours of admission, 2nd APACHE II (Acute Physiology And Chronic Health Evaluation II) at admission, 3rd APACHE II after 24 hours and 4th MAS (Modified APACHE II Score) at 24 hours. GCS and MAS may have superiority over the other systems in being easy to perform and not requiring laboratory data. Modified APACHE II Score (MAS) can be calculated without using biochemical parameters employed in (APACHE II) Score (Mood et al., 2011).

\section{Aim of the Study}

This study aims to evaluate the role of GCS and MAS as effective scoring systems in predicting mortality in acute cardiotoxicity. 


\section{Patients and Methods}

Study design: A prospective study was carried on 100 patients with acute cardiotoxicity by drugs and toxins known to cause cardiac injury admitted to Sohag University hospitals during the period from April 2018 to September 2019.

Patients: According to equation $[\mathrm{n}=(\mathrm{Z} 1-\alpha+\mathrm{Z} \beta) 2(\mathrm{~S} 1+$ S2)2/( $\mu 1-\mu 2) 2]$ by Hassanian-Moghaddam et al. (2014) to determine sample size with significant results by using this equation we need at least 59 patients to have significant results so we decided to collect 100 patients' sheets to have significant results.

Inclusion criteria: All patients admitted to Sohag University Hospitals with acute cardiotoxicity by drugs and toxins known to cause cardiac injury and we evaluate the injury by electrocardiogram (ECG) and serum CKMB and cardiac troponin I. The type of medication or toxin was determined according to the history given by the patient him/herself or next of kin if unconscious on admission. Additionally, screening for common drugs of abuse and digoxin level in cases of drug abuse toxicity and digoxin toxicity respectively.

Ethical conditions: After approval of director of Sohag University hospitals ,all studied patients or relatives signed informed consent before participation and they were allowed to refuse or accept this participation with complete confidentiality.

Exclusion criteria: The patients with underlying cardiac diseases (e.g. previous myocardial infarction) in addition to those who take chemotherapeutic drugs will be excluded.

The following data were collected from the sheet of each patient:

1. Socio-demographic data

2. ECG, serum CK-MB and cardiac troponin I

3. Vital signs

4. GCS

5. Physical findings

6. Outcome of the patients: The patients were classified according to the outcome into discharged and died patients.

\section{- GCS}

GCS from (3-15 points) was calculated from assessment of 3 components: motor (6 points), verbal (5 points) and eye (4 points) (Eizadi et al., 2011).

\section{- MAS}

MAS calculated from 5 physiological parameters \{mean arterial pressure, temperature, respiratory rate, heart rate and each of which were marked from 0 to 4 , with 0 being normal and 4 being the most abnormal then the $5^{\text {th }}$ parameter GCS score (15-GCS) was, then, added\}. The sum of these values was added to a mark adjusting for patient age and a mark adjusting for chronic health problems (severe organ insufficiency or immunocompromised patients). MAS can be calculated without parameters of biochemical tests [arterial oxygen tension ( $\mathrm{PaO} 2)$, arterial $\mathrm{pH}$, serum sodium, serum potassium, serum creatinine, haematocrit, white blood cell count] that are usually used in APACHE II Score (Mood et al., 2011).

\section{Statistical Analysis}

The collected data were tabulated, coded, and verified prior to computerized data entry and were statistically analyzed using Statistical Package for the Social Science (SPSS) software package, version 16. Results were expressed in tables and charts.

\section{Results}

A total of 100 patients of acute cardiotoxicity were included in this study with mean age 16.3 years \pm 17.392 and ranged from 2 to 70 years. The majority of patients (57\%) fall in the age group ( $\leq 15$ years) followed by age group (16-30years) represented by (28\%). Male gender constituted (51\%) of the studied patients and the majority of the cases from. According to residence, cases were mainly received from rural areas (82\%) (table, 1$)$.

As regard route and mode of intoxication, (table, 2) revealed that the majority of the studied intoxicated patients were exposed to drugs and toxins by oral route (81\%), bites and stings (14\%), inhalation (3\%) and injection (2\%) and mostly accidental (54\%) followed by suicidal mode (37\%).

As regards facial complexion in relation to toxic agents enrolled in this study (table, 3 ) showed that $40 \%$ of cases presenting with pallor were due to animal poisons, followed by cardiovascular drugs in $20 \%$ and phosphides in $20 \%$. In 4 out of 9 cases presenting with cyanosis, animal poisoning was the cause. Other causes included hydrocarbons plus organophosphates (OPs) (in 2 cases) and drugs of abuse (2 cases). All cases of angioedema resulted from paraphenylenediamines (PPD). There was statistically significant difference between types of toxic agents as regards facial complexions by using Chi-square test $(\mathrm{p}<0.001)$.

As regards pupil examination in relation to toxic agents enrolled in this study (table, 4) showed that constricted pupil was caused mainly by pesticides $50 \%$ followed by drugs of abuse $23.1 \%$. Dilated reactive pupil was found in $50 \%$ of CNS drugs. There was statistically significant difference between groups classified according to type of toxins as regards pupil examination by using Chi-square test $(\mathrm{p}<0.001)$.

Chi-Square statistical analysis for comparing different toxic agents as regards outcome is shown in (table, 5) and revealed that the most dangerous toxins observed to cause mortality was aluminum phosphide by (66.7\%), then calcium channel blockers (CCBs) by (25\%), beta adrenergic blockers (BBs) by (16.7\%) and scorpion (15.4\%). As regards recovery with complications succinylcholine and carbon monoxide (CO) toxicity were implicated by $(100 \%)$, organophosphates (OPs) by (12.5\%) and PPD by (25\%). There was statistically significant difference between types of toxins and drugs as regards outcome $(\mathrm{p}<0.001)$.

Table (6) shows that GCS at 24 hours of admission was high in majority of patients (57\%), 
moderate in (23\%), and low in (20\%) with mean 11.68 \pm 3.4.Table (7) represents the distribution of MAS points in the first 24hours among total number of patients. It was found that MAS ranged from 2 points to 25 points, with mean value of $9.83 \pm 4.89$ points.

Tables (8) and (9) revealed that MAS and GCS could be used as predictors of outcome and mortality of acute cardiovascular toxicity .There is highly significant increase of MAS score and very highly significant decrease of GCS in relation to mortality and complicated discharge compared to complete recovery. Table (10) and figure (1) represent ROC curve analysis to assess the predictors of outcome of acute cardiovascular toxicity. The area under the curve for MAS score was 0.908 and GCS score was 0.924 . Also, it was found that MAS score at cut off value $>11.5$ had corresponding sensitivity $100 \%$ and specificity $74.5 \%$, GCS at cut off $<9.5$ had sensitivity $100 \%$ and specificity $72.3 \%$. The accuracy rate of GCS was (92.4\%) which was slightly higher than MAS which was $(90.8 \%)$.

Table (1): Number and percentage of the studied patients as regard age, gender and residence

\begin{tabular}{|c|c|c|c|}
\hline Patient characteristics & & Number & Percentage (\%) \\
\hline \multirow{3}{*}{ Age groups(years) } & $\mathbf{1 5 y e a r s}$ & 57 & $57 \%$ \\
\cline { 2 - 4 } & $\mathbf{1 6 - 3 0 y e a r s}$ & 28 & $28 \%$ \\
\cline { 2 - 4 } & $\mathbf{3 1 - 4 5 y e a r s}$ & 7 & $7 \%$ \\
\cline { 2 - 4 } & $\mathbf{4 5 - 7 0 y e a r s}$ & 8 & $5 \%$ \\
\hline \multirow{2}{*}{ Gender } & Male & 51 & $49 \%$ \\
\cline { 2 - 4 } & Female & 49 & $18 \%$ \\
\hline \multirow{2}{*}{ Residence } & Urban & 18 & $82 \%$ \\
\cline { 2 - 4 } & Rural & 82 & \multicolumn{2}{|c|}{} \\
\hline
\end{tabular}

Table (2): Route and mode of intoxication among studied patients:

\begin{tabular}{|l|c|c|c|}
\hline \multirow{4}{*}{ Route of exposure } & & Number & Percentage (\%) \\
\hline & Oral & 81 & 81 \\
\cline { 2 - 4 } & Bite / Sting & 14 & 14 \\
\cline { 2 - 4 } & Inhalation & 3 & 3 \\
\cline { 2 - 4 } & Injection & 2 & 5 \\
\hline \multirow{3}{*}{ Mode of poisoning } & Accidental & 54 & 37 \\
\cline { 2 - 4 } & Suicidal & 37 & 6 \\
\cline { 2 - 4 } & Overdose & 3 & 3 \\
\cline { 2 - 4 } & Therapeutic & 0 & \\
\end{tabular}

Table (3): Chi-Square statistical analysis for comparing toxic agents as regards facial complexions in 100 studied patients:

\begin{tabular}{|c|c|c|c|c|c|c|c|c|c|c|c|c|c|c|}
\hline \multirow[t]{4}{*}{ Toxic agents } & \multicolumn{12}{|c|}{ Complexions } & \multirow{2}{*}{\multicolumn{2}{|c|}{ Total }} \\
\hline & \multicolumn{2}{|c|}{ Normal } & \multicolumn{2}{|c|}{ Cyanosis } & \multicolumn{2}{|c|}{ Sweating } & \multicolumn{2}{|c|}{ Pallor } & \multicolumn{2}{|c|}{ Flushing } & \multicolumn{2}{|c|}{ oedema } & & \\
\hline & \multicolumn{12}{|c|}{ Number\& percentage in relation to changes in facial complexion } & & \\
\hline & $\mathbf{N}$ & $\%$ & $\mathbf{N}$ & $\%$ & $\mathbf{N}$ & $\%$ & $\mathbf{N}$ & $\%$ & $\mathbf{N}$ & $\%$ & $\mathbf{N}$ & $\%$ & $\mathbf{N}$ & $\%$ \\
\hline CVS drugs & 12 & 17.6 & 1 & 11.1 & 0 & 0 & 2 & 20.0 & 0 & 0 & 0 & 0 & 15 & 15 \\
\hline CNS drugs & 21 & 30.9 & 0 & 0 & 0 & 0 & 1 & 10.0 & 3 & 100 & 0 & 0 & 25 & 25 \\
\hline Animal poisoning & 5 & 7.4 & 4 & 44.4 & 1 & 16.7 & 4 & 40.0 & 0 & 0 & 0 & 0 & 14 & 14 \\
\hline Pesticides & 14 & 20.6 & 0 & 0 & 1 & 16.7 & 0 & 0 & 0 & 0 & 0 & 0 & 15 & 15 \\
\hline Phosphides & 3 & 4.4 & 0 & 0 & 0 & 0 & 2 & 20.0 & 0 & 0 & 0 & 0 & 5 & 5 \\
\hline Hydrocarbons & 2 & 2.9 & 0 & 0 & 0 & 0 & 0 & 0 & 0 & 0 & 0 & 0 & 2 & 2 \\
\hline Hydrocarbons +OPs & 0 & 0 & 2 & 22.2 & 0 & 0 & 0 & 0 & 0 & 0 & 0 & 0 & 2 & 2 \\
\hline Drugs of Abuse & 5 & 7.4 & 2 & 22.2 & 4 & 66.7 & 1 & 10.0 & 0 & 0 & 0 & 0 & 12 & 12 \\
\hline CO & 1 & 1.5 & 0 & 0 & 0 & 0 & 0 & 0 & 0 & 0 & 0 & 0 & 1 & 1 \\
\hline Theophylline & 4 & 5.9 & 0 & 0 & 0 & 0 & 0 & 0 & 0 & 0 & 0 & 0 & 4 & 4 \\
\hline PPD & 1 & 1.5 & 0 & 0 & 0 & 0 & 0 & 0 & 0 & 0 & 4 & 100 & 5 & 5 \\
\hline Total & 68 & 100 & 9 & $! 00$ & 6 & 100 & 10 & 100 & 3 & 100 & 4 & 100 & 100 & 100.0 \\
\hline \multirow[t]{2}{*}{ Chi-square test } & \multicolumn{8}{|c|}{$\mathrm{X} 2$} & \multicolumn{6}{|c|}{1.57} \\
\hline & \multirow{2}{*}{\multicolumn{6}{|c|}{\begin{tabular}{|c|} 
P-value \\
nificant) $* * P<0$ (hiahly sianificant) $*$
\end{tabular}}} & & & \multicolumn{4}{|c|}{$0.000 * * *$} & & \\
\hline$N:$ number ${ }^{*} P<0.05$ (significant) ${ }^{* *} P<0.01$ (highly significant) $*$ & & & & & & & \multicolumn{6}{|c|}{$* * P<0.001$ (very highly significant) } & & \\
\hline $\begin{array}{l}\text { NS: Non- significant } \\
\text { Ops=organophosphates }\end{array}$ & \multicolumn{6}{|c|}{$\begin{array}{l}C V S=\text { cardiovascular system acting } \\
C O=\text { carbon monoxide }\end{array}$} & \multicolumn{6}{|c|}{$\begin{array}{l}C N S=\text { central nervous system acting } \\
P P D=\text { paraphenylenediamines }\end{array}$} & & \\
\hline
\end{tabular}


Table (4): Chi-Square statistical analysis for comparing toxic agents as regards pupil examination in 100 studied patients:

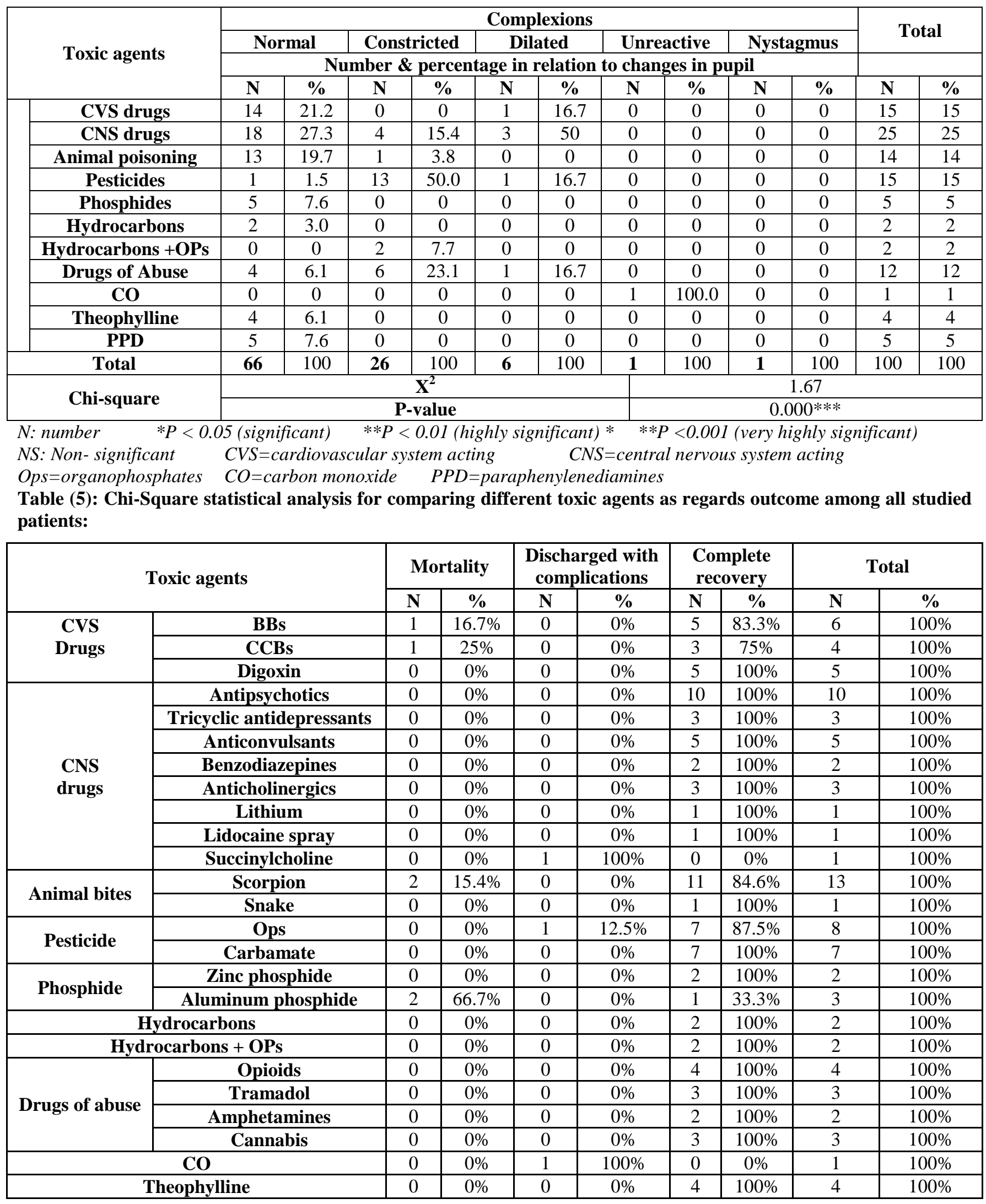


Table (5): Continued

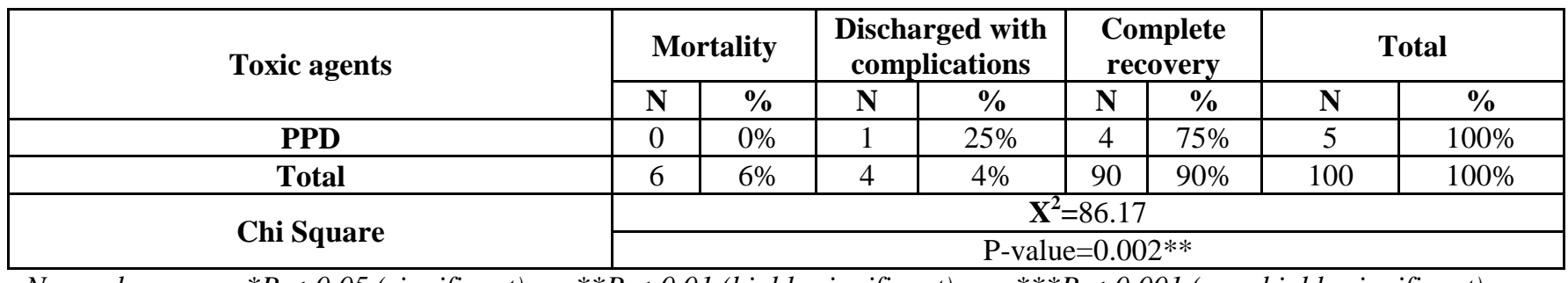

$N$ : number $\quad * P<0.05$ (significant) $\quad * * P<0.01$ (highly significant) $\quad * * * P<0.001$ (very highly significant)

NS: Non- significant $\quad$ CVS=cardiovascular system acting CNS $=$ central nervous system acting

Ops=organophosphates $\quad \mathrm{CO}=$ carbon monoxide $\quad P P D=$ paraphenylenediamines

Table (6): GCS and GCS score with mean, median, mode and range of GCS among all studied patients:

\begin{tabular}{|c|c|c|c|c|}
\hline Severity of toxicity & GCS & GCS score $=(15-G C S)$ & Number of patients & $\%$ \\
\hline Mild & $\geq 13$ & $0-2$ & 57 & $57 \%$ \\
\hline Moderate & $12-9$ & $3-6$ & 23 & $23 \%$ \\
\hline Severe & $\leq 8$ & $7-12$ & 20 & $20 \%$ \\
\hline \multicolumn{3}{|c|}{ Total } & 100 & $100 \%$ \\
\hline \multicolumn{3}{|c|}{ Mean \pm SD $=11.68 \pm 3.4$} & -15 points & \\
\hline
\end{tabular}

GCS: Glasgow Coma scale

SD: Standard deviation

Table (7): MAS mean, mode, median, range and percentage distribution of points at 24 hours of the admission of studied patients:

\begin{tabular}{|c|c|c|c|}
\hline \multicolumn{2}{|c|}{ MAS points groups } & Number & Percentage (\%) \\
\hline Mild & $2-10$ & 60 & $60 \%$ \\
\hline Moderate & $11-15$ & 26 & $26 \%$ \\
\hline Severe & $16-25$ & 14 & $14 \%$ \\
\hline & Total & 100 & $100 \%$ \\
\hline
\end{tabular}

MAS: Modified APACHE II Score

SD: Standard deviation

Table (8): Independent t-test statistical analysis of MAS score and GCS among studied patients:

\begin{tabular}{|c|c|c|c|c|c|}
\hline Variable & & Complicated recovery\&mortality & Uncomplicated recovery & Independent t-test & T \\
\hline & & $\mathbf{N}=\mathbf{1 0}$ & $\mathbf{N}=\mathbf{9 0}$ & $\mathbf{p}-\mathbf{v a l u e}$ \\
\hline MAS & Mean \pm SD & $\mathbf{1 4 . 8} \pm \mathbf{6 . 4 2}$ & $\mathbf{9 . 2 8} \pm \mathbf{4 . 4}$ & $\mathbf{3 . 5 8}$ & $\mathbf{0 . 0 0 1}$ \\
\hline GCS & Mean \pm SD & $\mathbf{8 . 1} \pm 3.87$ & $\mathbf{1 2 . 1} \pm 3.1$ & -3.729 \\
\hline$* P<0.05$ (significant) & $* * P<0.01$ (highly significant) & $* * * P<0.001$ (very highly significant) & $\mathbf{0 . 0 0 0} * * *$ \\
\hline
\end{tabular}

NS: Non- significant SD: Standard deviation MAS: Modified APACHE II Score GCS: Glasgow Coma scale

Table (9): Linear regression analysis of MAS score and GCS to detect predictors of mortality:

\begin{tabular}{|c|c|c|c|c|c|}
\hline \multirow{2}{*}{ Predictors } & \multicolumn{2}{|c|}{ Unstandardized Coefficients } & Standardized Coefficients & \multicolumn{2}{c|}{ Independent t-test } \\
\cline { 2 - 6 } & $\mathbf{B}$ & Standard Error & Beta & T & $\mathbf{- 4 . 2 9 7}$ \\
\hline MAS & $\mathbf{- 0 . 0 1 9}$ & $\mathbf{0 . 0 0 5}$ & $\mathbf{0 . 0 0 0} * * *$ & $\mathbf{0 . 3 9 8}$ & $\mathbf{4 . 4 7 0}$ \\
\hline GCS & $\mathbf{0 . 0 2 9}$ & $\mathbf{0 . 0 0 6}$ & $\mathbf{0 . 0 0 0} * * *$ \\
\hline$P<0.05$ (significant) & $* * P<0.01$ (highly significant) & $* * * P<0.001$ (very highly significant) \\
NS: Non- significant & \multicolumn{2}{l}{ MAS: Modified APACHE II Score } & GCS: Glasgow Coma scale
\end{tabular}

Table (10): Sensitivity, specificity and accuracy rate of MAS score and GCS as predictors of mortality:

\begin{tabular}{|c|c|c|c|c|c|c|c|c|}
\hline Variable & $\begin{array}{c}\text { Cut- off } \\
\text { point }\end{array}$ & AUC & p-value & $\begin{array}{c}\text { Sensitivity } \\
(\mathbf{\%})\end{array}$ & $\begin{array}{c}\text { Specificity } \\
\text { (\%) }\end{array}$ & PPV (\%) & NPV (\%) & $\begin{array}{c}\text { Accuracy } \\
\text { rate }\end{array}$ \\
\hline MAS score & $>11.5$ & 0.908 & $0.001^{* *}$ & $100 \%$ & $74.5 \%$ & $20.0 \%$ & $100 \%$ & $90.8 \%$ \\
\hline GCS & $<9.5$ & 0.924 & $0.001^{* *}$ & $100 \%$ & $72.3 \%$ & $18.75 \%$ & $100 \%$ & $92.4 \%$ \\
\hline
\end{tabular}




\section{ROC Curve}

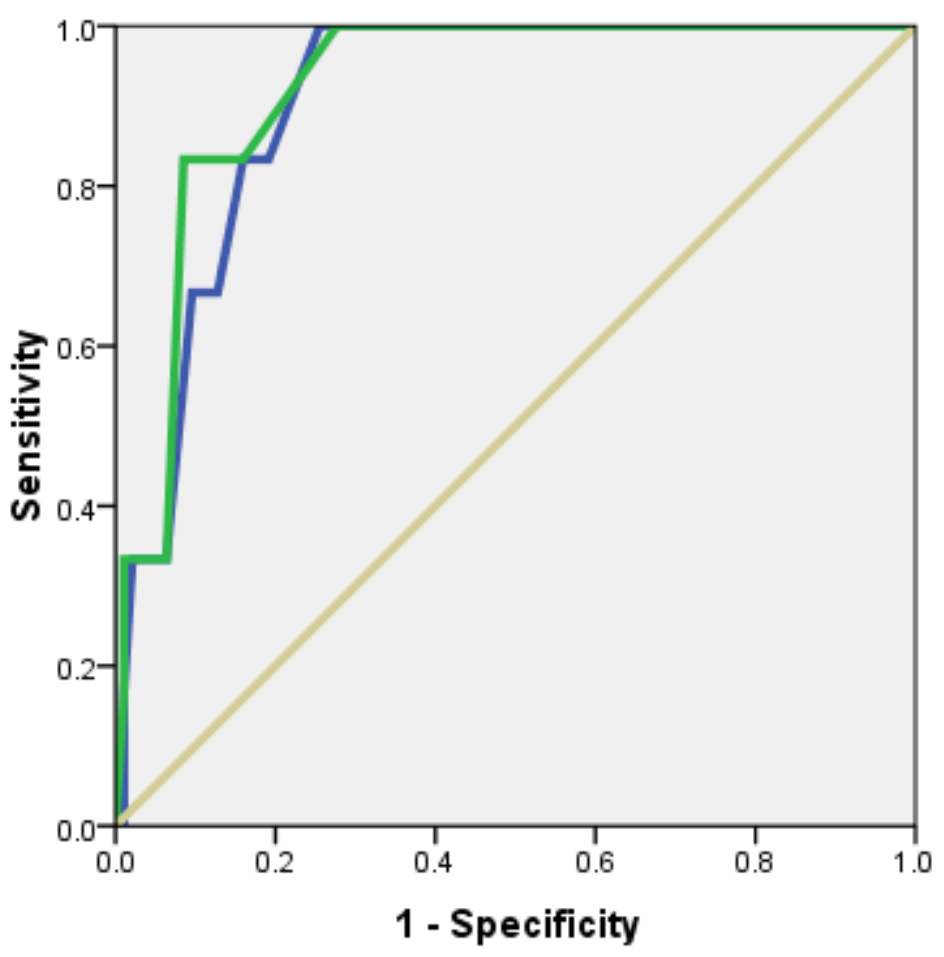

Source of the Curve

-MAS

- GCSscore

Reference Line

Diagonal segments are produced by ties.

Figure (1): Receiver Operator Characteristic (ROC) Curve of MAS and GCS score

\section{Discussion}

Due to shortage of ICU beds rapid assessment by easy and simple scoring systems is a must nowadays. Cases of intoxication with cardiac involvement are liable to high mortality rate and need close monitoring and assessment (Mood et al., 2011). This study aimed to evaluate the role of GCS and MAS as effective scoring systems in predicting mortality in acute cardiotoxicity. The present study was undertaken on 100 acutely poisoned patients by drugs and toxins with cardio-toxic effects who were admitted to Sohag University hospitals.

In the present study, the mean age was $16.3 \pm 17.4$ years and the majority of patients (57\%) fall in the age group ( $\leq 15$ years) years followed by age group (16-30years) representing (28\%). In contrast, Hussien et al., (2018) who studied cardiovascular drugs in poison control center of Ain Shams University Hospitals, found that the majority of studied patients were in the age group of (18-24) years presenting (50\%) of cases followed by the age group (25-40) years (37.5\%). Also, Karakilic et al. (2016) in Turkey studied relationship between BNP and cardiovascular toxicity found that the mean age was $33.36 \pm 12.23$ years, similar to an Iranian study of QT dispersion by HassanianMoghaddam et al. (2014) which was $31 \pm 12$ years (range from 7 to 65 years). This difference explained by Hassan and Siam (2014) as most of the poisonings by medications and pesticides were due to accidental ingestions by infants and young children.

In the current study $51 \%$ of the studied patients were males and $49 \%$ were females, which is nearly similar to the study by HassanianMoghaddam et al. (2014) in Iran who found that males represent $56.2 \%$ and females (43.8\%). The majority of the studied patients from rural areas (82\%) which coincides with both a study of poisoning in Aswan Governate 
by Mohamed et al. (2019) and with Punjab toxicological study of Singh et al. (2003).

In this study the route of poisoning was mainly by oral route $(81 \%)$, followed by bites and stings (14\%),while a minor percentage by inhalation (3\%) and injection (2\%).This partly agreed with the study of El Masry and Tawfik (2013) in Ain Shams poison control center as oral route was in $(94.9 \%)$ of cases.

In the current study the mode of poisoning was mostly accidental (54\%) followed by suicidal (37\%), while overdose and therapeutic errors represented (6\%) and (3\%) respectively. This is different from the study by El Masry and Tawfik (2013) as they reported that poisoning occurred suicidally (49\%), accidentally (42.7\%), drug overdose (7.5\%), therapeutic error $(0.4 \%)$ and homicidal in $0.4 \%$ of cases. However results in the current study agree with Ismail et al. (2015) who found accidental poisoning in Sohag constitutes (66.67\%\%), suicidal (33.33\%) and homicidal (0\%) .This was explained as the suicide rate in Upper Egypt is lower than Great Cairo due to religious effects and strong relationship between family members which was also supported by Aboul-Hagag et al. (2013).

As regard changes in facial complexion in the current study they were normal in $68 \%$ of patients; pallor, cyanosis and facial flushing presented in $10 \%, 9 \%$ and $3 \%$ of patients respectively. Animal bites were responsible for (40\%) of pallor then CVS drugs (20\%) and phosphides (20\%), (44.4\%) of cyanosis cases were due to animal poisoning then (22.2\%) due hydrocarbons plus OPs and drugs of abuse. All cases of angioedema were due to PPD. This came with Mahaba (2000) who described that pallor due cardiac injury or cyanosis due respiratory affection were major manifestations of animal bites. Also, Shalaby et al. (2010) mentioned that $72 \%$ of PPD studied poisoned patient came with angio-facial and laryngeal oedema.

In the present study pupil examination were normal in $66 \%$ of patients, $26 \%$ presented with constricted pupil, $6 \%$ with dilated pupil, constricted pupil caused mainly by pesticides
$50 \%$ followed by drugs of abuse $23.1 \%$ among the cases. Dilated reactive pupil was found in $50 \%$ of CNS drugs. This came with Ismail et al. (2015) in Sohag who found that pupil examination was normal in $60 \%$ of poisoned patients, $28.89 \%$ with miosis and $10 \%$ with mydriasis and also, miosis was almost caused by pesticides poisoning, while, mydriasis was more observed in CNS drugs and drugs of abuse. Pinpoint pupils is considered one of the clinical manifestations of cholinergic toxidrome signs due pesticides and opioid toxidrome. On the other hand, mydriasis is one of the clinical manifestations of sympathomimetics and anticholinergics toxidromes (Baskin, 2014).

As regard outcome in the current study 94\% survived from them 4 patients suffered complications on discharge and $6 \%$ of patients died. The most dangerous toxin causing mortality was aluminum phosphate by (66.7\%), CCBs by $25 \%$, BBs by $16.7 \%$ and scorpion by $15.4 \%$. As regards recovery with complications cases poisoned by succinylcholine and $\mathrm{CO}$ toxicity developed irreversible neurologic injury, OPs by (12.5\%) as the patient discharged with tracheostomy due to irreversible laryngeal stricture and PPD by (25\%) as the patient developed chronic renal failure. This agrees with Shadnia et al. (2005) as they highlighted that aluminum phosphide is a dangerous poison with majority of deaths occur within the first 12-24 hours, usually due to cardiovascular arrest. While, HassanianMoghaddam et al. (2014) found that (66.6\%) survived and (33.3 \%) died and noted that the most common overdosed drugs to have QT dispersion were methadone, followed by TCA and aluminum phosphide.

As regard clinical scores in the current study GCS was low $(\leq 8)$ within 24 hours of admission of patients in (20\%), moderate (12-9) in $(23 \%)$, while was high $(\geq 13)$ in majority of patients (57\%). Also, (60\%) of patients had MAS $\leq 10$ points, $(26 \%)$ had score (11-15) points and $(14 \%)$ had score $\geq 16$ points, the mean of MAS was $=9.83 \pm 4.89$ points and the range from 2 points to 25 points. This partially came with poisoning severity score used by $E l$ 
Masry and Tawfik (2013) in 2011 annual report of Ain Shams poison control center who classified poisoned patients to low severity (75.1\%), moderate (20.7\%) and high severity (4.2\%). Also, partially in agree with Heshmat et al., (2012) in Tanta study of ECG changes in acute poisoning who also classified GCS low $(\leq 8)$ in $(12.7 \%)$ of 282 studied patients, moderate (12-9) in $(42.6 \%)$, while was high $(\geq 13)$ in $(44.7 \%)$ of patients. GCS less than eight had been more associated with mortality in children presenting with poisoning also, GCS of 8 or less were more liable to be intubated (Eizadi Mood et al., 2011).

In the current study by using linear regression analysis with the indices studied in the current work it showed that MAS score and GCS score were highly significantly increased with death hence could be used as predictors of outcome. This agrees with Mood et al. (2011) in Iran who revealed that GCS and MAS by using logistic regression were identified as independent risk factors for predicting outcome in suspected poisoning.

In the present study ROC curve analysis to assess the predictor of outcome of acute cardiovascular toxicity, the area under the curve for MAS score was 0.908 and GCS score was 0.924 . Also, it was found that MAS score at cut off value $>11.5$ had corresponding sensitivity $100 \%$ and specificity $74.5 \%$, GCS at cut off $<9.5$ had sensitivity $100 \%$ and specificity $72.3 \%$. The accuracy rate of GCS (92.4\%) was slightly higher than that of MAS (92.4\%) both with excellent discrimination characteristic as according to Mood et al. (2011) AUCs between 0.7 and 0.8 were classified as "acceptable" and between 0.8 and 0.9 as "excellent" discrimination.

Our results were in accordance with those of Eizadi Mood et al. (2011) in Iran who showed that mixed drug poisoning patients with GCS $\leq 10$ are more liable to develop complications comparing to patients with GCS score more than 10. GCS at cut off point 10 showed accuracy 93\%, sensitivity $91 \%$ and specificity 92\%. Also, Mood et al. (2011) in Iran study of suspected poisoning showed that GCS within 24 hours of admission show accuracy rate $90 \%$ with cut-off point 5 show sensitivity $83 \%$ and specificity $94 \%$. In addition, MAS at cut off point 10 showed sensitivity $100 \%$ and specificity $61 \%$ and both GCS and MAS within 24 hours of admission had excellent discrimination.

\section{Conclusion}

MAS was significantly increased with mortalities, while, GCS was significantly decreased with mortalities with high accuracy rate hence could be used as predictors of outcome and they promising early simple scaling scores of prediction of mortality in acute cardiovascular toxicity with improving pathway of care, protocols of management and best use of hospital resources.

\section{Limitations of the Study}

The present study was conducted in Sohag hospitals and because there is no poison control center in Sohag, we hardly collected 100 patients with acute cardiovascular toxicity that can give us significant results. We did not make an adjustment in our results for the intensity of treatment, which may affect the rate of mortality. Despite these drawbacks, these data still provide important information and the current study is one of few studies in assessment of GCS and MAS together as predictor of mortality in acute cardiovascular toxicity.

\section{Recommendation}

The present study recommends the use of MAS and GCS as useful markers for prediction of mortality in patients with acute cardiotoxicity by cardiac drugs and non-cardiac drugs and toxins. Clearly, patients with elevated MAS (> 11 points) and decreased GCS $(<10)$ require monitoring and consideration of critical care unit admission and studies are necessary to evaluate whether initiation of certain treatments lipid emulsion therapy or high insulin glucose for BBs or CCBs should be empirically initiated for patients with elevated MAS or decreased GCS.

\section{Acknowledgment}

After Allah the author of this thesis dedicated the work to the soul of her father and thanks her supervisors for their kindness and 
great help and they thank the medical and nursing staff of Sohag University Hospitals for their help.

\section{References}

Aboul-Hagag K E, Ahmed FA, and Mansour AE (2013): Forensic analysis of suicide mortality in Sohag governorate (Upper Egypt) in the period 2005-2009. Egyptian Journal of Forensic Sciences. 2013 Jun 1;3(2):53-60

Baskin LB (2014): Intoxication and toxidromes. Lab Literacy for Canadian Doctors: A Guide to Ordering the Right Tests for Better Patient Care, 173.

Eizadi Mood N, Sabzghabaee AM, Yadegarfar G H, et al., (2011): Glasgow coma scale and its components on admission: are they valuable prognostic tools in acute mixed drug poisoning? Critical Care Research and Practice, 10.1155: ID 952956, 5 pages.

El Masry M and Tawfik H (2013): 2011 Annual report of the poison control centre of Ain Shams University Hospital, Cairo, Egypt. Ain Shams Journal of Forensic Medicine and Clinical Toxicology, 20.1: 10-17.

Hassan BA and Siam M G (2014): Patterns of acute poisoning in childhood in Zagazig, Egypt: an epidemiological study. International scholarly research notices, 2014: 245279-245279.

Hassanian-Moghaddam H, Amiri H, Zamani N, et al., (2014): QT dispersion and prognostication of the outcome in acute cardiotoxicities: A comparison with SAPS II and APACHE II scoring systems. Cardiovascular

Toxicology, 14.2: 129-133.

Heshmat MM, Maklad AI, Elsheikh RG, et al., (2012): Study of electrocardiographic changes associated with acute poisoning in Tanta poison center. Ain Shams Journal of Forensic Medicine and Clinical Toxicology, 19.2: 37-52.

Hussien R, Ashry SK, Agwa SH, et al., (2018): Plasma MiRNA-208b as a biomarker for detection of cardiotoxicity induced by acute cardiovascular drugs poisoning. Ain Shams Journal of Forensic Medicine and Clinical Toxicology, 31: 15-22.

Ismail PAM, Hilal MA, Mohamed SA, et al., (2015): Study on acute adult poisoning cases in Sohag University Hospitals in the period from October 2013 to September 2014. Thesis of master's degree, Srv3.eulc.edu.eg.

Johnson NJ, Gaieski DF, Allen SR, et al., (2013): A review of emergency cardiopulmonary bypass for severe poisoning by cardiotoxic drugs. Journal of Medical Toxicology, 9.1: 54-60.

Karakilic E, Solakoglu GA and Karakilic ID (2016): Relationship between BNP and cardiovascular toxicity. Acta Medica Mediterranea, 32.6: 1791-1796.

Mahaba HM (2000): Snake bite: epidemiology, prevention, clinical presentation and management. Annals of Saudi medicine, 20.1: 66-68.

Mohamed OH, George S M and Yassa HA (2019): Evaluation of poisoning patterns in Aswan Governorate in the period from 1st of June 2017 to 31st of December $2017 \quad$ (Prospective Study). Zagazig Journal of Forensic Medicine, 17.2: 84-95.

Mood NE, Sabzghabaee AM and KhaliliDehkordi Z (2011): Applicability of different scoring systems in outcome prediction of patients with mixed drug poisoning-induced coma. Indian Journal of Anaesthesia, 55.6: 599-604.

Shadnia S, Rahimi M, Pajoumand A, et al., (2005): Successful treatment of acute aluminum phosphide poisoning: possible benefit of coconut oil. Human \& Experimental Toxicology, 24.4: 215-218.

Shalaby SA, Elmasry MK, Abd-Elrahman AE, et al., (2010): Clinical profile of acute paraphenylenediamine intoxication in Egypt. Toxicology and Industrial Health, 26.2: 81-87.

Singh K, Oberoi SS, and Bhullar DS (2003): Poisoning trends in the Malwa region of Punjab. Journal of Punjab Academy of 
Forensic Medicine and Toxicology, 3:26-29

\section{التتبؤ بنتيجة التسمم القلبي الحاد على أساس مقياس الغيبوبة الجلاسكو كوما سكال و المقياس المعدل من اباتثي تو

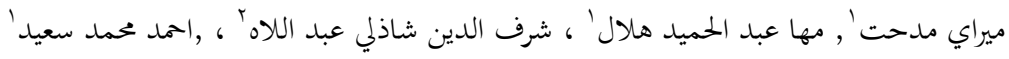 \\ الملخص العربي}

المقدمة: يمكن أن يكون للمرضى المصابين بالتسمم القبلي الحاد أعراض جانبية تؤدي إلى ضرورة الدخول الي وحدات العناية المركزة. ونظرًا لمحدودية أسرة العناية المركزة

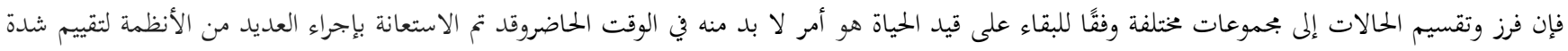

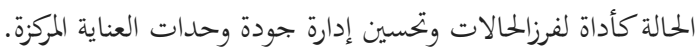

الهدف من الدراسة: تحدف هذه الدراسة إلى تقييم دور الجلاسكو كوما سكال والنسخة المعدلة من اباتشي توكنظام تسجيل فعال في التنبؤ بالوفيات في حالات التسمم القبي الحاد.

طريقة البحث: أجريت دراسة مستقبلية على . . 1 مريض يعانون من التسمم القبي الحاد بالعقاقير والسموم المعروفة بتسببها في اعتلال عضلة القلب بمستشفيات

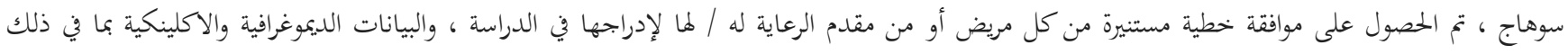

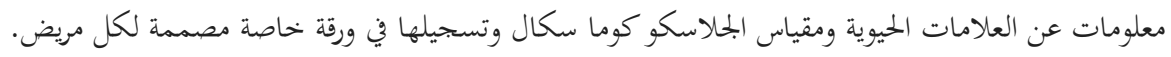
نتائج البحث :

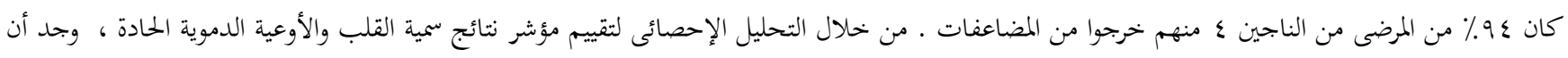

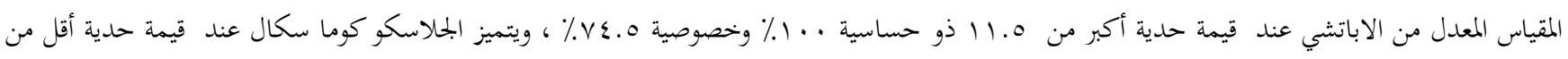

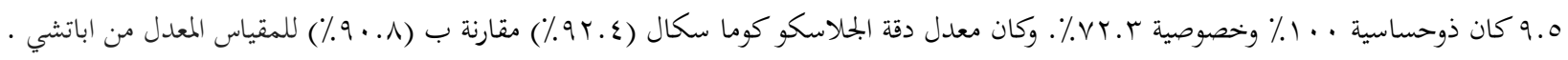
الخلاصة: يمكن الاستعانةبالجلاسكو كوما سكال والمقياس المعدل من اباتشي كأدوات بسيطة في التنبؤ بالوفيات في التسمم القبلي الحاد. التوصيات:يوصى بالأستعانة بالجلاسكو كوما سكال والمقياس المعدل من اباتشي تو كأدوات فرز بسيطة لمرضى التسمم القببي الحاد في وحدة العناية المركزة لتحسين

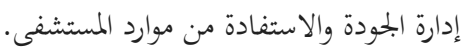

